\title{
Distal monosomy 9p
}

INSERM

\section{Source}

INSERM. (1999). Orphanet: an online rare disease and orphan drug data base. Distal monosomy 9p. ORPHA:1642

Distal monosomy $9 p$ is a rare chromosomal anomaly syndrome, resulting from a partial deletion of the short arm of chromosome 9, with a highly variable phenotype typically characterized by intellectual disability, craniofacial dysmorphism (trigonocephaly, upslanting palpebral fissures, hypoplastic supraorbital ridges), abnormal digits (long middle phalanges with short distal phalanges), as well as frequent association with genitourinary abnormalities (cryptorchidism, hypospadias, ambiguous genitalia, 46,XY testicular dysgenesis). Congenital hypothyroidism and cardiovascular defects have been reported in some cases. Patients present an increased risk for gonadoblastoma. 